\title{
Comité de Educación Médica de la Sociedad de Cirujanos de Chile. Siguiendo el rumbo
}

\section{Medical Education Committee of the Society of Surgeons of Chile.}

Following the course

\author{
Alejandro Campos G.
}

Este año 2018, me correspondió suceder como presidente del comité de educación, al Prof. Dr. Jorge Martínez, quien deja el cargo dejando una vara muy alta, por su brillante desempeño y cercanía con los becados de Cirugía.

La educación médica, en el ámbito de la especialidad de cirugía general, implica por parte del docente, una entrega de conocimientos y de supervisión directa e indirecta de procedimientos y habilidades, estando esto enmarcado en un ambiente de buen trato, ético, altruista y desinteresado, cuya parte medular es la entrega de conocimientos y el logro de aprendizaje por parte de los alumnos en formación, lo cual permite, en el caso especifico de la cirugía, el bienestar y mejoría de nuestros pacientes.

La enseñanza de la cirugía, implica además, una carencia de egoísmo en la entrega del conocimiento.

Al formar parte de un equipo quirúrgico, muchas veces vemos como nuestros cirujanos en formación crecen tanto del punto de vista personal como profesional, y en este último aspecto, somos testigos del desarrollo y superación profesional de nuestros residentes, lo que lleva implícito a su vez, un crecimiento del equipo del cual forman parte.

La Sociedad de Cirujanos de Chile, fomentando el progreso de la enseñanza de la cirugía en nuestro país, interactúa y participa, con la directiva representante de los residentes de cirugía general a nivel nacional, en la realización de cursos durante el año, para la programación del curso precongreso y en la seccional de becados en el Congreso Chileno de Cirugía.

Además, La Sociedad De Cirujanos de Chile, está trabajando en abrir centros regionales quirúrgicos seleccionados a lo largo del país, para que reciban en una estadía de dos meses, a los residentes de cirugía en formación; esto ya es una realidad en Coquimbo, Talca y Punta Arenas, y esperamos pronto, lograr lo mismo en Arica.

La experiencia de los residentes, al estar en estos centros regionales, ha sido tremendamente valiosa desde el punto de vista profesional, siendo además para el centro quirúrgico, un gran aporte, pues la presencia de un residente, trabajador, exigente, crítico, ávido de conocimientos y de operar, estimula a los cirujanos locales para unificar criterios en cuanto a la entrega del conocimiento y contribuyen a la mejora continua de la calidad del trabajo médico.

Solo mencionar además, la apertura de centros de simulación quirúrgica, que estamos realizando a lo largo del país, contribuyendo enormemente a la difusión y desarrollo de la enseñanza de la cirugía en Chile.

En suma, nuestra Sociedad de Cirujanos, permanentemente buscando el progreso y desarrollo de la cirugía nacional, está contribuyendo a través de distintas instancias con esta tarea, apoyando tanto al cirujano en formación, como a los cirujanos especialistas participes de la Sociedad.
Presidente Comité de Educación Médica.

Correspondencia a: camposal33@yahoo.com 